\title{
Variability Assessment of Different Maintainer Lines for Hybrid Rice Development Based on Qualitative Traits
}

\author{
L F Lipi $^{1 *}$, M J Hassan¹, AAkter ${ }^{1}$, P L Biswas ${ }^{1}$, M U Kulsum¹, A Ansari ${ }^{1}$ and M Z Islam²
}

\begin{abstract}
The assessment of genetic diversity among nineteen maintainer lines was studied based on thirteen qualitative traits. The single linkage clustering, morphological dendogram were performed to assess the traits. Most of the traits showed variation in different maintainer lines except auricle colour. On the basis of flag leaf attitude, a maximum four groups were formed with erect, semi-erect, horizontal and descending type leaf angle. The maintainer line BRRI20B has awn tip, which is unique from the rest of the studied maintainer lines. Nineteen maintainer lines were grouped into four different clusters and a considerable level of variability was displayed for most of the traits examined. The clustering pattern revealed, cluster I was the largest and consisted seven maintainer lines. Among them maintainer lines BRRI52B and BRRI60B were the most closely associated. Cluster II represent diverse sources materials and its revealed non-correspondence of geographic diversity with genetic divergence. Thus the cluster analysis has revealed the genetic variation and the traits contributing for the variation. Hence, this maintainer lines can be utilized for trait improvement in breeding programmes for the traits contributing for major variation.
\end{abstract}

Key words: Maintainer line, genetic variability, qualitative traits

\section{INTRODUCTION}

Rice (Oryza sativa L.) is considered as one of the most important cereal crops and the staple food for more than half of the world's population (Jiang et al., 2013).Rice production area of Bangladesh is about 10 million hectares of land in which the area planted to hybrid rice was around 0.7 Mha, which contributed 3-4 MT of additional rice to the total rice production in the country (AIS, 2018). Although Bangladesh is self-sufficient in cereal production, there is a great challenge of rapid growth of the population, decreasing arable land, reducing productivity and global climate change. We need to increase the production vertically to meet up the food demand of growing population and need to produce more rice per unit area. Hence hybrid rice technology has proved to be one of the most feasible and readily adoptable approaches as they yield about 15-20 percent more than the best of the improved or high yielding varieties (Virmani, 1994). The performance and heterosis of hybrids are associated with genetic divergence between their parental lines. Selection of suitable parental lines like cytoplasmic male sterile line (CMS), maintainer line and restorer lines to develop heterotic combinations can be facilitated by determining genetic divergence among them. Due to the importance of rice as one of the major world food crops, its genetic diversity has created great interest of researchers. Genetic diversity in the available gene pool is the foundation or the raw material of all plant improvement programmes. Several genetic diversity studies have been successfully

${ }^{1}$ Hybrid Rice Division, 2 Genetic Resources and Seed Division, BRRI, Gazipur, Bangladesh. *Corresponding author's E-mail: ferdousi.lipi@yahoo.com 
utilized in different crop species based on quantitative and qualitative traits in order to select genetically distant parents for hybridization (Islam et al., 2018; Bedoya et al., 2017; Ahmed et al., 2016; Islam et al., 2016). The precise assessment of variability within the parental lines is necessary not only for better understanding of the differentiation pattern but also to assist in selecting appropriate materials to broaden the genetic base and the genetic improvement of cultivars. Careful selection of parental lines on the basis of their genetic diversity may lead to the development of hybrids with higher yield potential than parents and standard check varieties (Julfiquar et al., 1985).

The majority of programmes involved in the improvement of rice productivity mainly focused on the yield aspects. On the other hand, quantitative traits and other important qualitative characters have been neglected. Morphological characterization using qualitative traits is a preliminary step to estimate the variability and relationship among cultivars. Qualitative characters are important for plant descriptions (Kurlovich, 1998) and are influenced by consumer preference, socio-economic scenario and natural selection (Hien et al., 2007). Incase of hybrid rice, so far very limited work has been done on diversity of parental lines using quantitative characters but no work has been accomplished on diversity of parental lines using agronomic qualitative traits. Hence, keeping the importance of hybrid rice and scant literature on these aspects, the present investigation was undertaken as a first attempt with the objective of variability assessment of different maintainer lines for hybrid rice development based on qualitative traits.

\section{MATERIALS AND METHODS}

Present investigations were conducted at the Bangladesh Rice Research Institute (BRRI) farm, Gazipur. Nineteen maintainer lines were characterized for 13 qualitative traits. Among them 17 maintainer lines were developed locally and two of them namely IR78355 IR75595 originated from International Rice Research Institute (IRRI) (Table 1). The experiment was laid out in a randomized complete block design (RCBD) with three replications during T. Aman season 2015. The BRRI developed maintainer lines were BRRI19B， BRRI20B， BRRI22B， BRRI25B, BRRI42B， BRRI52B， BRRI55B， BRRI60B, BRRI63B， BRRI67B， BRRI69B， BRRI70B, BRRI71B, BRRI73B, BRRI76B, BRRI79B, BRRI81B. The maintainer lines originated from IRRI were IR75595B, IR78355B. Twenty-oneday old seedlings were transplanted at the rate of one seedling per hill with plant to plant distance of $15 \mathrm{~cm}$ and row to row distance of $20 \mathrm{~cm}$. The standard cultivation practices prescribed for hybrid rice were followed precisely. Observations on maintainer lines were recorded for 13qualitative traits viz ligule colour, ligule shape, auricle colour, collar colour, blade colour, blade pubescence, basal leaf sheath colour, susceptibility to BLB, angle of flag leaf, stigma colour, awn: distribution, panicle exsertion, and seedcoat colour. The phenotypically distinguishable qualitative traits are used as a preliminary tool for assessing genetic variability.

These characters were scored based on 'Descriptors for cultivated rice (Oryza sativa L.)’ developed by GRSD, BRRI (2018). Ten random plants from each entry were selected for recording observations. Frequency distributions for all of the qualitative traits were computed. Cluster analysis was done to group the genotypes into a dendogram by using PAST software. 
Table 1. Composition of clusters based on similarity co-efficient for thirteen qualitative characters in nineteen maintainer lines.

\begin{tabular}{|c|c|c|c|}
\hline Cluster & No. of maintainer lines & Maintainer line & Frequency $(\%)$ \\
\hline I & 7 & $\begin{array}{l}\text { BRRI52B, BRRI60B BRRI63B, RRI76B, BRRI67B, } \\
\text { RRI81B, BRRI25B }\end{array}$ & 36.84 \\
\hline II & 5 & $\begin{array}{l}\text { BRRI71B, IR78355B, IR75595B, BRRI73B, } \\
\text { BRRI79B }\end{array}$ & 26.32 \\
\hline III & 4 & BRRI55B, BRRI69B, BRRI22B, BRRI70B & 21.05 \\
\hline IV & 3 & BRRI42B, BRRI19B, BRRI20B & 15.79 \\
\hline
\end{tabular}

\section{RESULTS AND DISCUSSION}

Qualitative characters are important for plant description (Kurlovich, 1998) and mainly influenced by the consumers preference, socioeconomic scenario and natural selection (Das and Ghosh, 2011). These qualitative characters are less influenced by the various environmental conditions. The present study exhibits considerable level of variability in most of the observed qualitative traits except auricle colour. Figure 1 shows the graphical representation of frequency distribution for 13 qualitative traits. The majority of the maintainer lines were characterized by white ligule colour $(89.47 \%)$, 2-cleft ligule shape $(63.15 \%)$. Again most of the maintainer lines showed pale green collar colour $(57.89 \%)$, green blade colour $(47.36 \%)$, intermediate blade pubescence $(63.15 \%)$, green basal leaf sheath colour $(73.68 \%)$, very low susceptibility to BLB $(84.21 \%)$, semi-erect angle of flag leaf $(68.42 \%)$ and white stigma colour $(89.47 \%)$. Panicle exertion included well exserted $(52.63 \%)$, moderately exerted $(31.57 \%)$, and just exserted (15.74\%). On the basis of awning character, most of the maintainer lines were found to be awn less (94.73\%), only one maintainer line BRRI20B showed awn tip only $(5.26 \%)$. This type of unique character could be efficiently used in identification and protection from biopiracy. Among the 19 maintainer lines most of the lines showed light brown seedcoat colour $(68.42 \%)$ followed by brown seedcoat colour $(31.57 \%)$. Similar findins were reported by Akter et al., (2017), Moukoumbi et al., (2011), Ahmed et al.,(2015), Parikh et al., (2012), Singh and Mishra., (2013), Pragnya et al., (2018) and Shamim, M Z and Sharma, V K (2014).

However, Parikh et al., (2012) observed green basal leaf sheath colour $(84.5 \%)$, white ligule colour (94.7\%). M Z Islam (2017) and Pragnya et al., (2018) found 2-cleft shaped ligule in all jhum rice from hilly areas landraces and soft rice genotypes respectively. Monika et al., (2007) and Bora et al., (2008) used the same traits to characterize nineteen and eleven cultivars of rice respectively. Ahmed et al. (2015) also reported that majority of the genotypes possess green blade colour (47\%) and white colour of stigma (90\%). Singh and Mishra (2013) reported pubescence of blade surface $(57 \%)$, semi erect flag leaf attitude (75\%), awns absent (91\%), well exserted panicle (57\%). Pragnya et al., (2018) also found semi-erect flag leaf attitude in 14 soft rice genotypes. Shamim and Sharma (2014) found light brown seedcoat colour (38.8\%) among different rice varieties for qualitative traits. 
Fig. 1. Morphological variations and frequency distribution for13 qualitative traits of 19 maintainer lines.
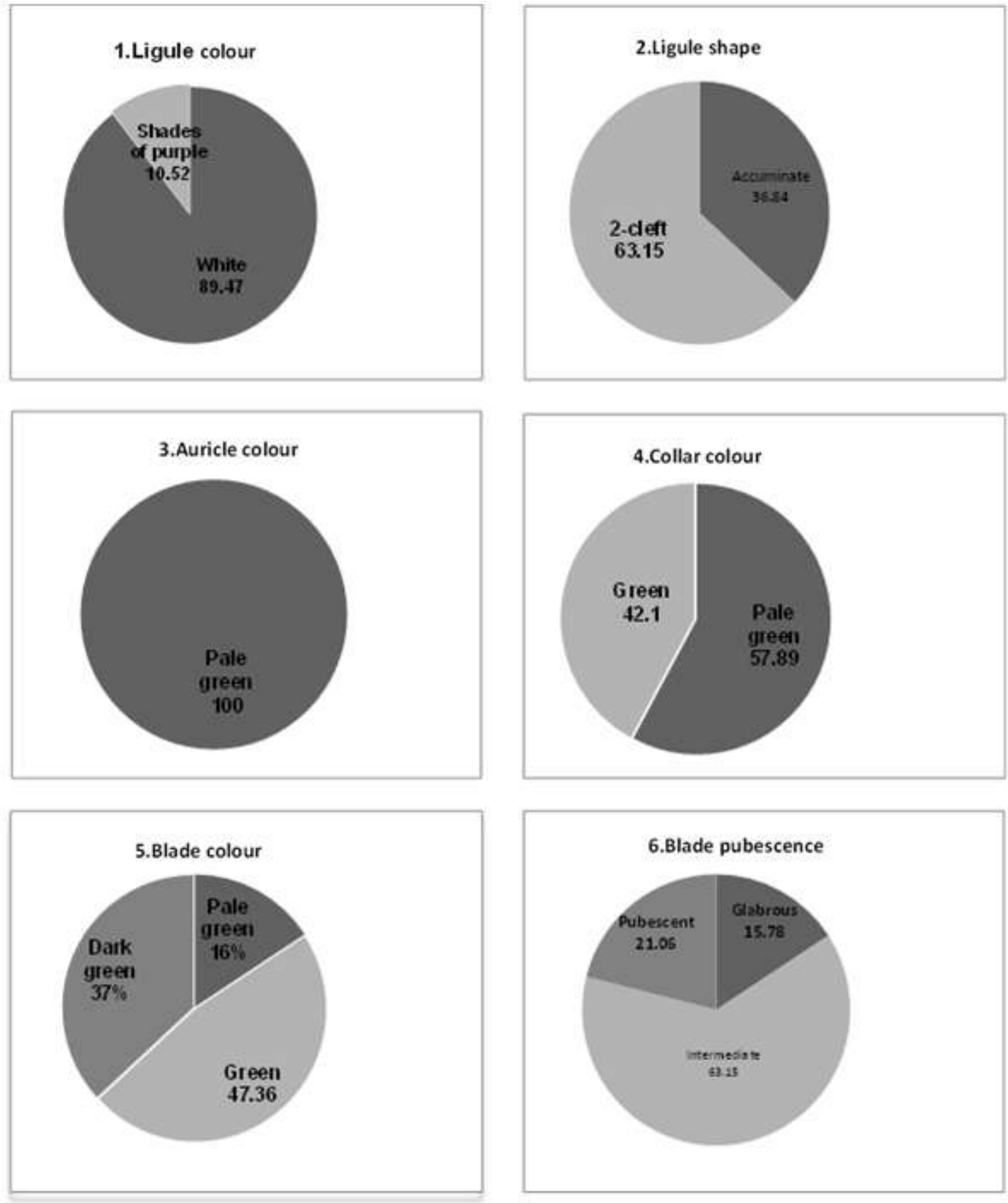

82 Lipi et al 
Fig. 1. Continued.
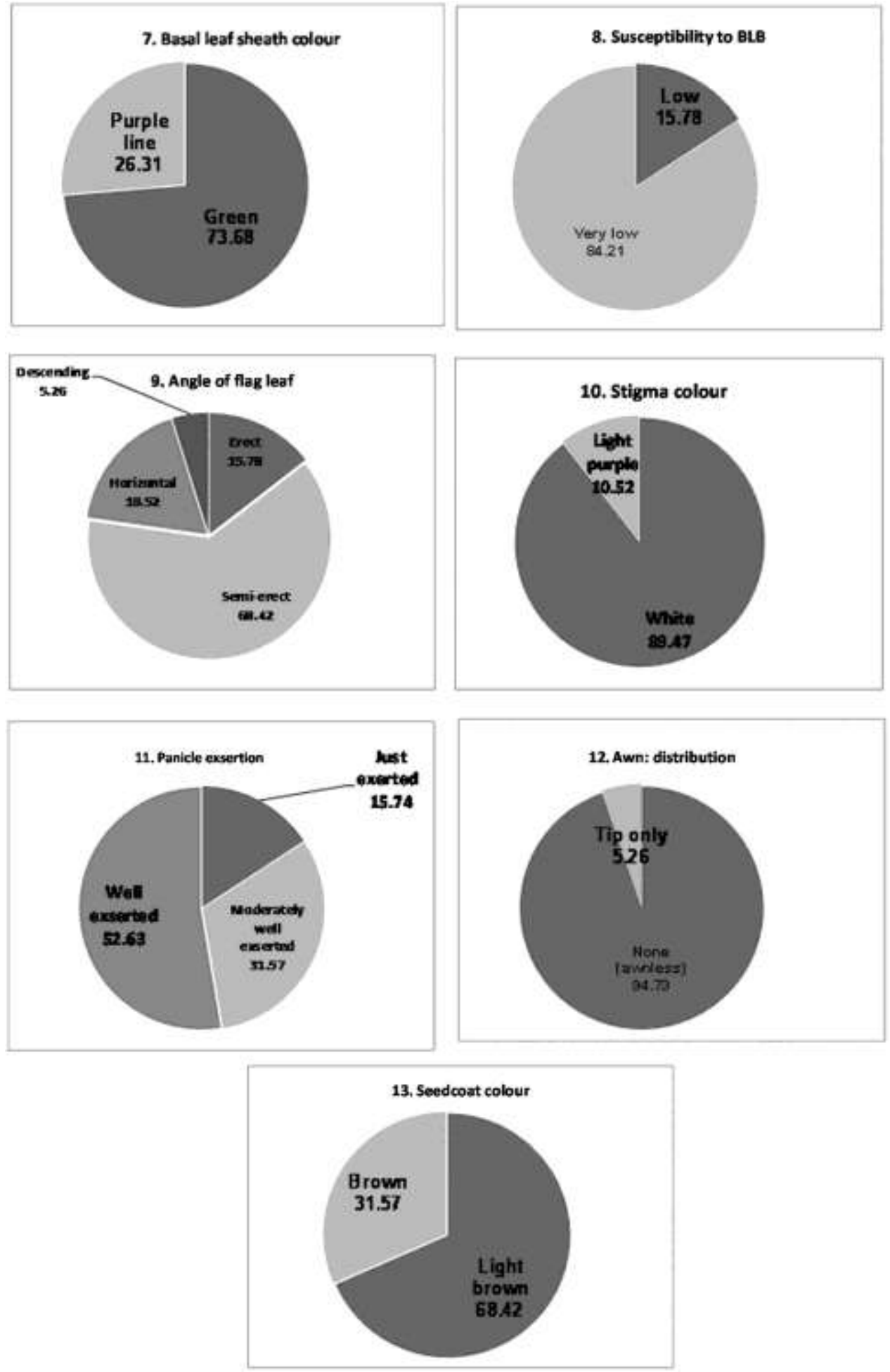

Variability Assessment of Different Maintainer Lines for Hybrid Rice Development 83 
All the maintainer lines were grouped into four major clusters at 0.25 minimum distance between clusters and its frequency distribution (Fig. 2). The value of 0.25 was fixed only for the convenience of explanation under this study. Cluster I contained maximum seven entries followed by five in cluster II, four in cluster III and three in cluster IV. Thus cluster I, cluster III and IV represented only BRRI developed maintainer lines but cluster II represented the both BRRI and IRRI developed maintainer lines. The genotypes from the same geographical origin mostly grouped together; however, the less frequent genotypes from different origins also grouped within the same cluster. Maintainer lines BRRI52B and BRRI60B grouped into same cluster at minimum distance within clusters.

Therefore, these two maintainer lines can be considered as morphologically closest and might possess same genetic background. According to Ali et al., (2000) cluster analysis has the singular efficacy and ability to identify crop accessions with the highest level of similarity. Even though the dendogram also proved the above statement in terms of similarity existing among the tested maintainer lines, a wide variability among them was identified. Suriyagoda et al., (2011) have reported a similar variability of rice varieties.
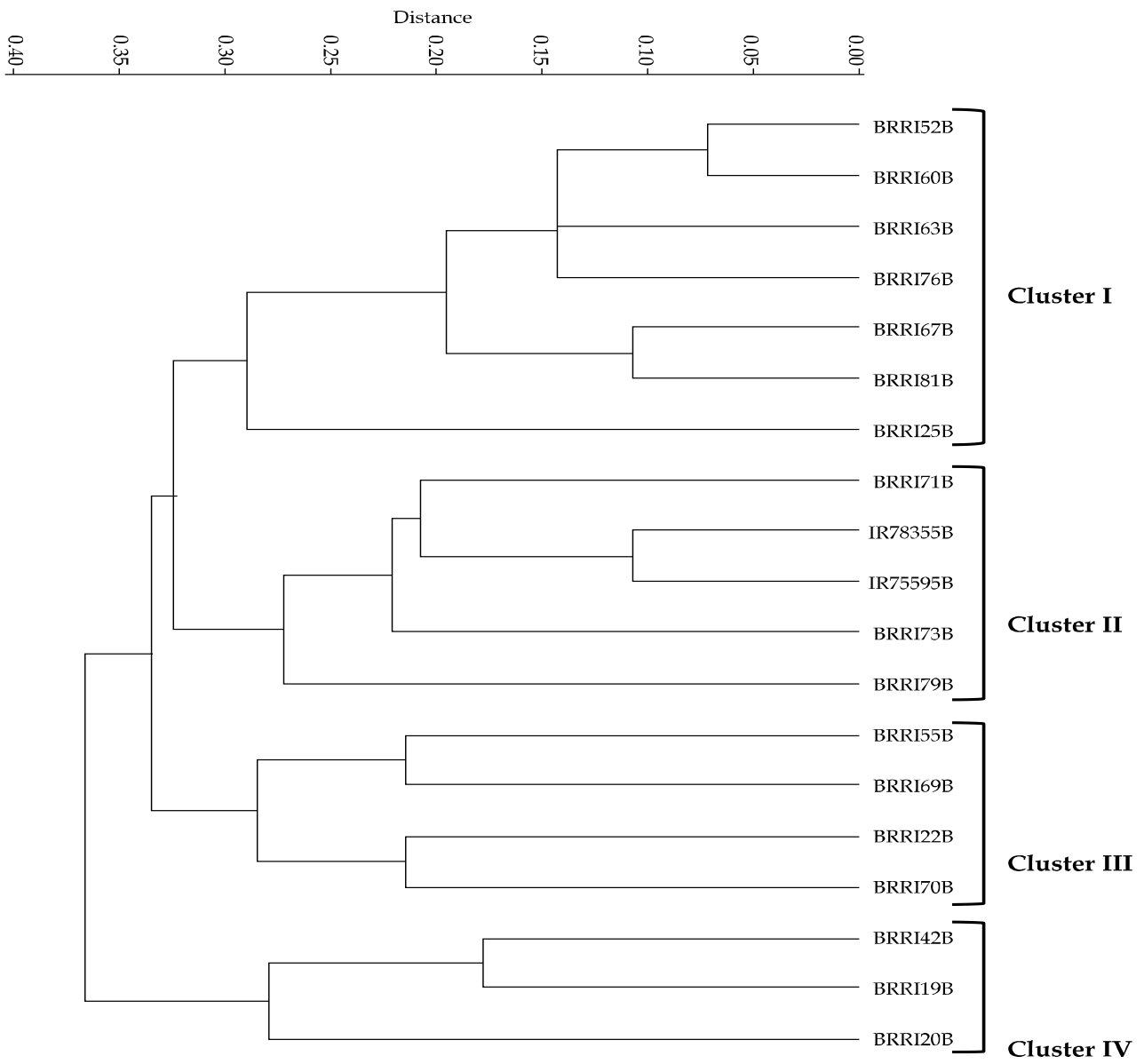

Fig. 2. Dendogram of 19 maintainer lines of hybrid rice obtained through single linkage cluster analysis. 
As per the scattered diagram (Fig. 3), the maintainer lines were apparently distributed into four clusters. The results indicated that the maintainer linesthat were placed far away from the centroid were more genetically diverse, while the genotypes that were placed near the centroid possessed more or less similar genetic background. Similar findings were also reported by other authors (Siddique et al., 2016a, 2016b).
However, the selection of parents for hybridization from different clusters may provide more variability and high heterotic effect. Similar finding was also reported by Pradhan and Roy (1990). Similarly, the tested qualitative traits can be utilized to broaden the genetic base and for the improvement of parental lines. Further, Tehrim et al., (2012) also proved that agro-morphological traits can be used effectively to characterize the rice cultivars.

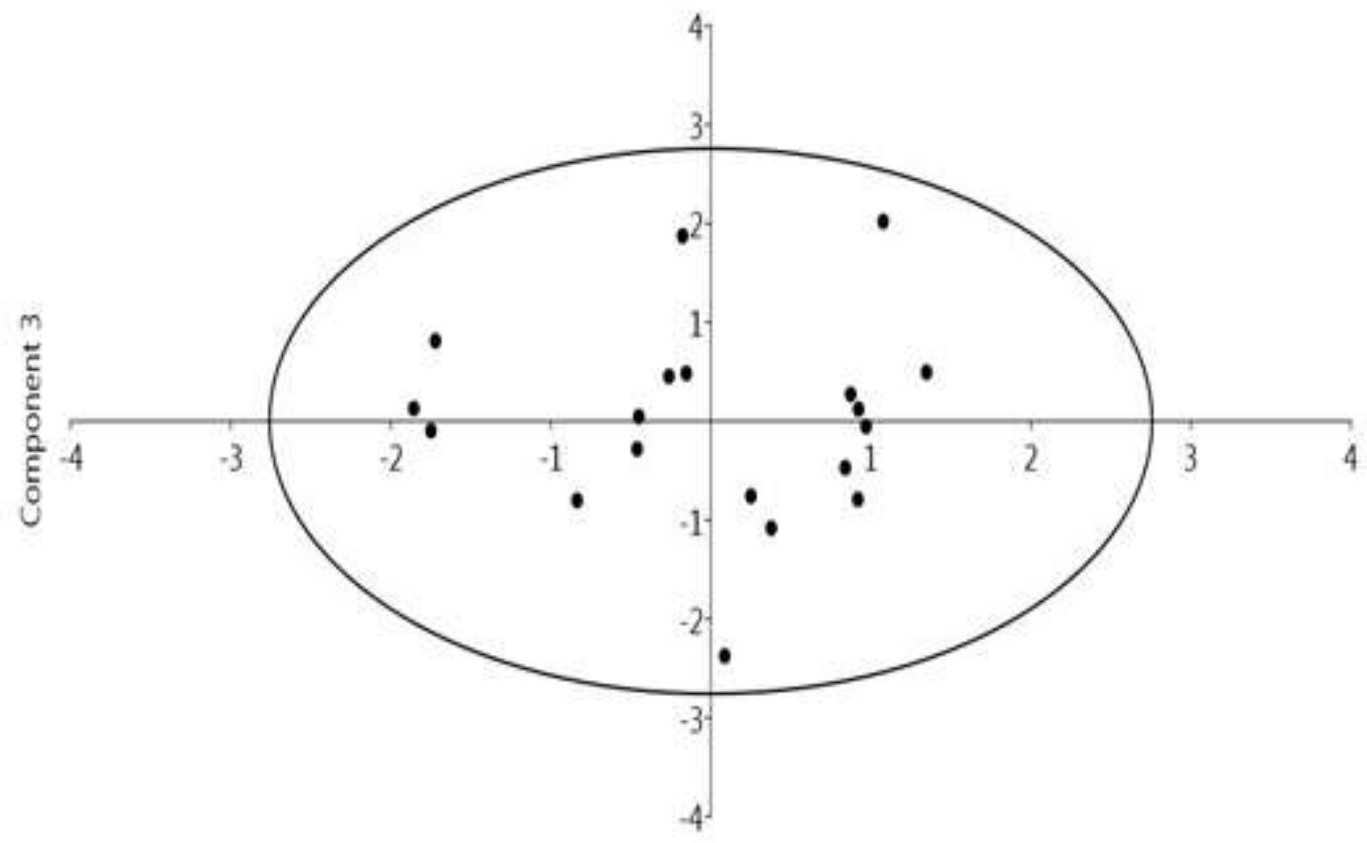

Component 1

Fig. 3. Scatter diagram of 19 maintainer lines based on their qualitative traits.

\section{CONCLUSION}

The present study shows a considerable level of variability among the studied maintainer lines. It interprets a considerable amount of morphological variation along with the qualitative traits of maintainer lines. The results show that cluster I, cluster III and IV represented only BRRI developed maintainer lines but cluster II represented both BRRI and IRRI developed maintainer lines. The genotypes from the same geographical origin mostly grouped together; however, the less frequent genotypes from different origins also grouped within the same cluster. The selection of parents for hybridization from different clusters will provide more variability and high heterotic effect. Among the 13 traits, panicle exsertion and flag leaf angle are considered as important traits for hybrid rice development and selection could be done considering these traits. 


\section{REFERENCES}

Ahmed, M S, M Khalequzzaman, M K Bashar and A K M Shamsuddin. 2015. Qualitative agro-morphological character diversity of similar or duplicate named rice (Oryza sativa L.) germplasm of Bangladesh. JBES. 7(4): 51-61.

Ahmed, M S, Bashar, M K and Shamsuddin, A K M. 2016. Study of qualitative characters of Balam Rice (Oryza sativa L.) landraces of Bangladesh. Rice Genomics Genet. 7 (1): 1-8.

AIS. 2018. Krishi Diary 2016, Agricultural Information Service, Khamarbari, Farmgate, Dhaka 1215, Bangladesh.

Akter, N, M Z Islam, A Bhuiya, M A Siddique and M Khalequzzaman. 2017. Distinctness of 45 irrigated rice (Oryza sativa L.) landraces of Bangladesh through agro-morphological traits. Eco-friendly Agril. J.10 (10): 100-107.

Ali, S S, S J H Jafri, T Z Khan, A Mahmood and M A Butt. 2000. Heritability of yield and yield components of rice. Pak. J. Agric. Res. 16: 89 - 91.

Bedoya, C A, S Dreisigacker, S Hearne, J Franco, C Mir and B M Prasanna. 2017. Genetic diversity and population structure of native maize populations in Latin America and the Caribbean. PLOS ONE. 12 (4): e0173488. https://doi.org/10.1371/journal.pone.0173488.

Bora, R, S D Deka and P Sen. 2008. Identification of rice varieties of Assam, based on grain characters and reaction to certain chemical tests. Seed Research. 36 (1): 51-55.

Das, S, A Ghosh. 2011. Characterization of rice germplasm of West Bengal. Oryza. 47(3): 201-205.

GRSD, BRRI. 2018. Descriptors for cultivated rice (Oryza sativa L.).Genetic Resources and Seed Division, Bangladesh Rice Research Institiute, Gazipur 1701, Bangladesh.

Hien, N L, WA Sarhadi, Y Hirata and Y Oikawa.2007. Genetic diversity of morphological responses and the relationships among Asia aromatic rice (Oryza sativa L.) cultivars. Tropics 16: 343-355.

Islam, M Z, M Khalequzzaman, M A Siddique, N Akter, M S Ahmed and M A Z Chowdhury. 2017. Phenotypic characterization of jhum rice landraces collected from Rangamati district in Bangladesh. Bangladesh Rice J. 21(1): 47-57, 2017.

Islam, M Z, M Khalequzzaman, M K Bashar, N A Ivy, M MHaque and M A K Mian. 2016. Variability

Lipi et al assessment of aromatic and fine rice germplasm in Bangladesh based on quantitative traits. The Sci. World J. http://dx.doi.org/10.1155/2016/ 2796720.

Islam, M Z, N Akter, T Chakrabarty, A Bhuiya, M A Siddique and M Khalequzzaman. 2018. Agromorphological characterization and genetic diversity of similar named aromatic rice (Oryza sativa L.) landraces of Bangladesh. Bangladesh Rice J. 22 (1): 45-56

Jiang, S H, H Zhou, D Z Lin, Y J Dong, S H Ye and X M Zhang. 2013. Identification and gene mapping of a thermo-sensitive leaf-colour mutant at seedling stage in rice. Chin J Rice Sci. 27: 359 - 364.

Julfiquar, A W, S S Virmani and A L Carpena. 1985. Genetic divergence among some maintainer and restorer lines in relation to hybrid breeding in rice (Oryza sativa L.). Theory of Applied Genet. 70(6): 671-678.

Kurlovich, B S. 1998. Species and intraspecific diversity of white, blue and yellow lupins. Plant genetic Resource Newsletters. 115: 23-32.

Monika, A, A Joshi, K Navaraj, R C Sharma, P Singh and T S Bharaj. 2007. Varietal characterization of rice (Oryza sativa L.) based on morphological descriptors. Seed Research. 35 (2): 188

Moukoumbi, Y D, M Sie, R Vodouhe, B N'dri, B Toulou, S A Ogunbayo and A Ahanchede. 2011. Assessing phenotypic diversity of interspecific rice varieties using agromorphological characterization. J. of Pl. Breed. and Crop Sci. 3(5): 74-86.

Parikh, M, N K Motiramani, N K Rastogi and B Sharma. 2012. Agro-morphological and quality characterization of Dubraj group from aromatic Rice germplasm of Chhattisgarh and Madhya Pradesh. Soc. for pl. res. 25 (2): 387394.

Pradhan, K and A Roy. 1990. Genetic divergence in rice. Oryza. 27(4): 415-418.

Pragnya, K, K V Radha Krishna, L V Subba Rao and K Suneetha. 2018. Studies on Morphological Characterization in Soft Rice (Oryza sativa L.) Genotypes. Int. J. Curr. Microbiol. App. Sci. 7(05): 1348-1374.

Shamim, M Z and V K Sharma. 2014. Assessment of variability and genetic diversity among different rice varieties for qualitative traits.Indian J. Agric. Res. 48 (3): 237-240.

Siddique, M A, M Khalequzzaman M M Islam, Kaniz Fatema and M A Latif. 2016a. Molecular 
characterization and genetic diversity in geographical indication (GI) rice (Oryza sativa L.) cultivars of Bangladesh. Braz. J. Bot. DOI 10.1007/s40415-016-0271-1

Siddique, M A, M Khalequzzaman, K Fatema, M Z Islam, M M Islam and M A Z Chowdhury. 2016b. Molecular characterization and genetic diversity of Aman rice (Oryza sativa L.) landraces in Bangladesh. Bangladesh Rice J. 20 (2): 1-1

Singh, S K and D K Mishra. 2013. Principal component analysis of inter sub specific RILs of rice for the important traits responsible for yield and yield quality. JNKVV Research Journal. 47(2):185-190.
Suriyagoda, L D B, R M M S, Thilakarathne, S P Nissankaand S Samitha. 2011. Morphological variation in selected rice (Oryza sativa L.) germplasm of Sri Lanka. J. Natn. Sci. Foundation Sri Lanka. 39: $129-137$.

Tehrim, S, Z H Pervaiz, M Y Mirza, M A Rabbani and M S Masood. 2012. Assessment of phenotypic variability in rice (Oryza sativa L.) cultivars using multivariate analysis. Pak. J. Bot. 44: 999 - 1006.

Virmani, S S. 1994. Prospects of hybrid rice in the tropics and subtropics. In: Hybrid rice technology: New development and future Prospects (Ed.). S S Virmani, IRRI, Manila, Philippines, pp.7-19. 